INDO GLOBAL JOURNAL OF

PHARMACEUTICAL SCIENCES

ISSN 2249- 1023

\title{
Reference Genes Validation in Phenacoccus solenopsis under Biotic and Abiotic Stress Conditions
}

\author{
Surjeet Kumar Arya ${ }^{*}$, Gaurav Jain, Praveen C. Verma \\ CSIR-National Botanical Research Institute, Council of Scientific and Industrial Research, Rana Pratap Marg, Lucknow, UP, India
}

Address for Correspondance: Surjeet Kumar Arya, surjeet_arya@yahoo.com

Keywords

Reference; RT-

qPCR; Validation;

Insect;

Normalization.

\begin{abstract}
Phenacoccus solenopsis (Mealybug) is a devastating phloem sap feeder. It is now recognized as an aggressive invasive pest of various economically important crops. Due to economic significance of this species has led to great insight in basic research involving gene-expression studies. Realtime PCR (RT-qPCR) expression analysis is a powerful analytical technique, but for normalization of data requires the use of stable reference genes. However, suitable reference genes are still not known in the case of $P$. Solenopsis. This study proposed to test the expression stability of 6 commonly used candidate reference genes including $\beta-T U B, G A P D H, R P L 32, \alpha-T U B, A C T$ and $S D H$ subjected to various regimes of experimental treatments. In the validated samples, expression stability of the reference genes was analyzed by employing three different statistical software's geNorm, NormFinder, and Refinder. Moreover, pairwise analysis showed that two reference genes were not sufficient to normalize the gene expression data under different condition. By contrast, ACT and GAPDH were the least stably expressed genes tested. The suitability of particular combination of reference genes was empirically validated by performing normalizations of expression data for the MIP's and $Z n \_M P$ genes under development and host feeding assay's. This study provides a list of reliable reference genes for transcript normalization in P. Solenopsis in different abiotic and biotic stress treatments, which will facilitate genetic studies in other closely related species. (C) 2016 iGlobal Research and Publishing Foundation. All rights reserved.
\end{abstract}

Conference Proceedings: International Conference on Advances in Plant and Microbial Biotechnology (PMB2017); JIIT, Noida: February 02-04, 2017

Indo Global Journal of Pharmaceutical Sciences( ISSN 22491023 ; CODEN- IGJPAI; NLM ID: 101610675) indexed and abstracted in EMBASE(Elsevier), SCIRUS(Elsevier),CABI, CAB Abstracts, Chemical Abstract Services(CAS), American Chemical Society(ACS), Index Copernicus, EBSCO, DOAJ, Google Scholar and many more. For further details, visit http://iglobaljournal.com 